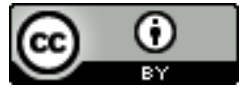

\title{
CURSOS ONLINE ABERTOS E MASSIVO NO BRASIL NO CONTEXTO DA INTERNACIONALIZAÇÃO DA EDUCAÇÃO SUPERIOR
}

\author{
MASSIVE OPEN ONLINE COURSES IN BRAZIL IN THE CONTEXT OF THE \\ INTERNATIONATION OF HIGHER EDUCATION \\ CURSOS ONLINE ABIERTOS Y MASSIVOS EN BRASIL EN EL CONTEXTO DE LA \\ INTERNACIONALACIÓN DE LA EDUCACIÓN SUPERIOR
}

\section{Tânia Barbosa Martins i \\ Marcelo da Silva Leite \\ Miriam Pavany Alexandre Moraes Ramos}

\begin{abstract}
RESUMO: O artigo analisa os Cursos Online Aberto e Massivo (Massive Open Online Course - MOOC), considerando suas finalidades e objetivos e as discussões a respeito da temática da internacionalização da educação superior. Os MOOCs surgiram recentemente no Canadá em 2008 atrelados aos princípios dos denominados Recursos Educacionais Abertos (REA) e das tecnologias da informação e comunicação (TICs) como meio de difusão do conhecimento de modo aberto e gratuito. Os MOOCs estão sendo inseridos nas instituições de ensino superior brasileiras sob influência de certas experiências universitárias internacionais. A metodologia de pesquisa se fundamenta numa análise da revisão da literatura, de caráter exploratório, e de seu exame a partir dos estudos e das tendências à internacionalização da educação. Apesar das diferentes motivações econômicas e institucionais do processo de internacionalização da educação superior, os MOOCs surgem inicialmente como uma proposta de caráter mais estritamente cientifico e acadêmico, mas articulado organicamente à corrente prática de uma proposta estritamente econômica de internacionalização da educação.
\end{abstract}

PAlavRAS-Chave: Internacionalização da educação. Instituições de Ensino Superior. Cursos Online Aberto e Massivo.

ABSTRACT: The article analyzes the Massive Open Online Course (MOOC), considering its aims and objectives and the discussions on the topic of the internationalization of higher education. MOOCs have recently emerged in Canada in 2008, linked to the principles of so-called Open Educational Resources (OER) and information and communication technologies (ICTs) as a means of disseminating knowledge in an open and free way. MOOCs are being inserted in Brazilian higher education institutions under the influence of certain international university experiences. The research methodology is based on an exploratory review of the literature, and its examination based on studies and trends in the internationalization of education. Despite the different economic and institutional motivations of the process of internationalization of higher education, the MOOCs initially appeared as a proposal of a more strictly scientific and academic character, but organically articulated to the current practice of a strictly economic proposal of internationalization of education.

KEYWORDS: Internationalization of education. Higher education institutions. Massive Open Online Courses.

RESUMEN: El artículo analiza los Cursos Online Abierto y Massivo (Massive Open Online Course - MOOC), considerando sus finalidades y objetivos y las discusiones sobre la temática de la internacionalización de la educación superior. Los MOOCs surgieron recientemente en Canadá en 2008 en relación con los principios de los denominados Recursos Educativos Abiertos (REA) y de las tecnologías de la información y la comunicación

Submetido em: 20/06/2017 - Aceito em: 09/07/2017 - Publicado em: 09/08/2017.

\begin{tabular}{|l|l|l|l|l|l} 
(C) Rev. Inter. Educ. Sup. & Campinas, SP & v.3 & n.3 & p.604-623 & set./dez. 2017
\end{tabular}


(TIC) como medio de difusión del conocimiento de manera abierta y gratuita. Los MOOCs se están insertando en las instituciones de enseñanza superior brasileñas bajo la influencia de ciertas experiencias universitarias internacionales. La metodología de investigación se fundamenta en un análisis de la revisión de la literatura, de carácter exploratorio, y de su examen a partir de los estudios y las tendencias a la internacionalización de la educación. A pesar de las diferentes motivaciones económicas e institucionales del proceso de internacionalización de la educación superior, los MOOCs surgen inicialmente como una propuesta de carácter más estrictamente científico y académico, pero articulado orgánicamente a la corriente práctica de una propuesta estrictamente económica de internacionalización de la educación.

PALABRAS CLAVE: Internacionalización de la educación. Instituciones de enseñanza superior. Cursos Online Abierto y Masivo.

\section{INTRODUÇÃ̃o}

As tecnologias de informação e comunicação (TICs) possibilitaram o surgimento de múltiplas e heterogêneas experiências de educação e produziram reflexões sobre novas formas didáticopedagógicas no processo de ensino-aprendizado. A partir de meados da década de 1990, as TICs adquiriram centralidade na legislação nacional e nas diretrizes das políticas educacionais, proliferando inúmeros programas e projetos educacionais, com incentivo direito do próprio Estado por meio das políticas públicas de expansão do ensino superior. O desenvolvimento das TICs contribuiu ainda para o reconhecimento da educação a distância (EaD) como modalidade de educação reconhecida e legitimada na LDB n. 9.394/96. Nesse processo, instituições estatais e privadas decidiram ofertar cursos de educação a distância, de tal modo que o quantitativo das matriculas na $\mathrm{EaD}$ cresceu relativamente mais do que no ensino presencial. A propósito do último Censo da Educação Superior de 2015, enquanto no ensino presencial o crescimento foi da ordem de $2,3 \%$ nas matrículas em relação ao ano de 2014, no ensino a distância o crescimento alcançou 3,9\% (BRASIL, 2016).

As experiências desenvolvidas no ensino superior com o uso das TICs, tanto nos processos de ensino-aprendizagem quanto na organização institucional, resultaram em uma quantidade significativa de trabalhos acadêmico-científicos que tratam de variados temas como a formação de professores, as condições de trabalho docente e os processos de ensinoaprendizado, atrelados ao uso das TICs ou sob influências das TICs nas instituições educacionais. As experiências com os recursos tecnológicos têm se renovado diariamente tanto no ensino superior quanto em todas as modalidades e níveis de escolaridades. Atualmente, os pesquisadores estão sendo desafiados a compreender outra atividade educacional de ensino e de aprendizado oferecida por instituições de ensino superior do mundo inteiro e, tal como na $\mathrm{EaD}$, comumente fundamentado nas TICs, os denominados Cursos Online Aberto e Massivo (Massive Open Online Course).

(C) Rev. Inter. Educ. Sup.
Campinas, SP

v.3

n. 3

p.604-623

set./dez. 2017 
Os MOOCs são apresentados como cursos online, de inscrição gratuita e abertos, destinados a qualquer pessoa, oferecidos gratuitamente a um grande número de participantes e exigindo apenas um único professor para coordenar todas as informações (BOTTENTUIT JR, 2015). Segundo Yuan et al. (2013) duas características dos MOOCs merecem ser destacadas: Acesso aberto e escalabilidade. No caso da acesso aberto, entende-se que para participar de um MOOC não precisa ser um aluno matriculado em uma escola tradicional e não é obrigado a pagar nenhuma taxa; e, a escalabilidade refere-se à uma proposta de MOOC em que o curso deve ser planejado para suportar um número indefinido de participantes sem depender de um certo número de participantes e professores para serem iniciados. Há que considerar que a definição de MOOCs está sendo desenvolvida no campo da educação, entretanto, de modo geral, a definição de MOOCs baseia-se em um modelo de educação a distância específico, em que o acesso aberto e a participação em larga escala são centrais.

O Massive Open Online Course iniciou-se na University of Manitoba, no Canadá em 2008, com a experiência de George Siemens e Stephen Downes, que criaram um curso intitulado Connectivism and connective knowledge com o objetivo de apresentar uma nova teoria de aprendizagem denominada Conectivismo. A ideia fundante dessa teoria de aprendizagem sustenta-se na premissa de que o conhecimento existe no mundo e não é inato como preconizam algumas teorias da aprendizagem. Apesar das controvérsias, a proposta foi reconhecida por estudiosos de várias universidades como uma das primeiras iniciativas de reunir a filosofia do curso aberto e foi designada de Massive Open Online Course (GOTO, 2015, p. 30). Desde então, prestigiadas instituições de ensino superior no mundo passaram a criar plataformas de ensino que reuniam em um ambiente virtual cursos de diferentes formatos em todas as áreas do conhecimento (FORNO; KNOLL, 2013). Observa-se que as plataformas de aprendizagem possibilitam o surgimento de parcerias e acordos entre instituições nacionais e internacionais. Atualmente, as plataformas mais conhecidas na América do Norte e na Europa, são: Plataforma EdX; Plataforma Coursera, além de outras plataformas, em outras regiões do mundo (GOTO, 2015).

No Brasil, os principais cursos de MOOCs são ofertados pela Veduca, plataforma gratuita e pública, criada em março de 2012. O Veeduca começou com um acervo de 5 mil aulas de 13 universidades do mundo. As universidades estaduais do Estado de São Paulo: Universidade Estadual Paulista "Júlio de Mesquita Filho" (UNESP), Universidade de Campinas (Unicamp) e Universidade de São Paulo (USP), por meio do Veduca oferecem cursos por meio de vídeoaulas e disponibiliza conteúdos internacionais traduzidos para o português de universidades como Stanford University, Massachusetts Institute of Technology, Columbia University, Michigan University e Harvard University. No portal do Veduca (Em: http://veduca.org/courses), acessado em 02 de junho de 2017, há vários cursos sendo oferecidos em várias áreas de conhecimento: Física Básica; Probabilidade e Estatística;

\begin{tabular}{l|l|l|l|l|l|} 
(ㅇ) Rev. Inter. Educ. Sup. & Campinas, SP & v.3 & n.3 & p.604-623 & set./dez. 2017 \\
\hline
\end{tabular}


Bioenergética; Ciência Política; Escrita Científica; Eletromagnetismo; Ética; Energias Renováveis; Finanças Pessoais e Investimentos em Ações; Libras; Jornal na Sala de Aula; e, Fundamentos de Administração.

De acordo com Boal e Stallivieri (2015, p. 8), no Brasil há várias instituições públicas e também privadas que oferecem cursos via MOOCs: Universidade de São Paulo (USP); Universidade de Brasília (UnB); Instituto Tecnológico da Aeronáutica (ITA); Fundação Getúlio Vargas (FGV); Pontifícias Universidades Católicas de São Paulo (PUC-SP) e do Rio de Janeiro (PUC-RJ); Universidade Federal de Campina Grande (UFCG), dentre outras. Zanini (2016, p.48) destaca a iniciativa do governo do Estado do Rio de Janeiro que criou o Programa de Apoio ao Desenvolvimento Cultural dos Municípios do Estado do Rio de Janeiro (PADEC), ação realizada em parceria com a Secretaria de Articulação Institucional do Estado do Rio de Janeiro, destinado atingir a meta de formar 2 mil cursistas (na denominação tradicional: alunos). Incialmente, o PADEC, ofereceu o curso de formação de gestores públicos e agentes culturais por intermédio dos MOOCs.

Os cursos oferecidos pelos MOOCs não são cursos superiores, completos e regulares, propriamente ditos, são oferecidos na perspectiva de complementação dos cursos superiores. No banco de dissertações e teses da Coordenação de Aperfeiçoamento de Pessoal de Nível Superior (CAPES), ainda que seja um tema recente, encontram-se um número relativamente considerável de estudos nas mais diversas áreas do conhecimento sobre os MOOCs. Constatase que há cursos destinados a estudantes de medicina, anatomia (BIAGIOTTI, 2016) e histologia (CANDIDO, 2013); destinados à estudantes de física e matemática (SCHOELLER, 2016); e a alunos das ciências humanas, "origens da vida no contexto cósmico" (apresentar referência); destaca-se, sobretudo, que há MOOCs destinados exclusivamente a alunos da educação básica, como, por exemplo, o curso de geometria (SOUZA, 2015). Pode-se aventar a possibilidade de cada vez mais se adotar o formato MOOC para complementação e a formação/certificação nas mais diversas áreas do conhecimento e nos mais diversos níveis de escolaridade, o que exigirá um estudo mais pormenorizado das possibilidades didáticopedagógicas, das transformações no perfil e no trabalho docente, bem como da institucionalidade educacional e na gerência das instituições educacionais.

A crescente adesão das instituições de ensino superior ao processo de internacionalização da educação superior e o encantamento com as possibilidades de aproveitamento dos recursos tecnológicos sobre o aspecto acadêmico, do ensino e da educação, impõe que os MOOCs sejam investigados considerando as estratégias de mercado das universidades brasileiras. Daí a necessidade de compreender, entre outros aspectos, os processos de implantação e funcionamento dos MOOCs, as parcerias e a competição estabelecidas com as instituições estrangeiras, as intencionalidades (objetivos e finalidades) das instituições na oferta de MOOCs, os tipos de cursos ofertados, os processos de acesso e permanência dos cursistas e o

(C) Rev. Inter. Educ. Sup. \begin{tabular}{|l|l|l|}
\hline Campinas, SP & v.3 & n.3 \\
\hline
\end{tabular} 
papel do professor na mediação do processo de ensino-aprendizagem.

O objetivo, entretanto, não é responder a todas aquelas indagações, mas se limitar a problematizar algumas situações e a tratar especificamente da expansão dos MOOCs no Brasil, problematizando as possíveis intencionalidades das instituições de ensino superior e considerando o processo de internacionalização da educação superior.

\section{A INTERNACIONALIZAÇÃO DA EDUCAÇÃO SUPERIOR}

Conforme Knight (2003a, 2003b) e Van Der Wende (2007), apesar de o tema da internacionalização da educação superior ser discutido de forma ampla em publicações científicas, não há ainda tecnicamente nenhuma possibilidade de definição consensual sobre o assunto. Os pensadores que pesquisam sobre a internacionalização da educação superior reconhecem que o tema não pode ser facilmente conceituado porque é um processo complexo e multifacetado. Apesar do esforço de inúmeros pesquisadores para descrever o fenômeno, a internacionalização da educação superior continua a ser um tema em debate.

Na década de 1980 a internacionalização da educação superior era entendida como atividades internacionais, trocas de experiências e investigações científicas entre países. A definição proposta por Arum e Van Der Wende (1992) é um bom exemplo dessa abordagem. Eles propuseram que a internacionalização se refere a "múltiplas atividades, programas e serviços internacionais que fazem parte de estudos internacionais, e cooperação técnica" (ARUM; VAN DER WENDER, 1992, p. 202). Para Van der Wende a definição obteve um entendimento mais amplo do ponto de vista do meio ambiente externo. A internacionalização é "qualquer esforço sistemático encaminhado a fazer que a educação superior responda aos requerimentos e desafios relacionados com a globalização das sociedades, da economia e dos mercados" (1997, p. 18).

Knight (1994) introduziu a definição de internacionalização da educação vinculada à abordagem organizacional. A internacionalização é um processo sustentável que precisa ser integrado ao nível institucional. Internacionalização foi definida como o "processo de integração de uma dimensão internacional e intercultural nas funções de ensino, pesquisa e serviço da instituição" (KNIGHT, 1994, p.7).

Assim, a internacionalização do ensino superior é redefinida por Knight como um processo que consiste na concepção e implementação de políticas e programas que têm por objetivo, por um lado, integrar a dimensão internacional e intercultural nas missões, objetivos e funções de ensino, investigação e extensão das instituições universitárias, e, por outro lado, canalizar os benefícios derivados da cooperação (Knight, 2005). Este processo envolve várias

\begin{tabular}{l|l|l|l|l|l} 
() Rev. Inter. Educ. Sup. & Campinas, SP & v.3 & n.3 & p.604-623 & set./dez. 2017 \\
\hline
\end{tabular}


ações: incentivar a mobilidade de estudantes e professores; promover a internacionalização do currículo; estimular formação conjunta/cooperada; desenvolver a investigação de atividades e a formação de redes, entre outros.

Uma outra definição sobre internacionalização do ensino superior apresentada pela Association of Internations Educators (NAFSA), pressupõe uma comunidade acadêmica mundial organizada em redes e parcerias:

[...] a internacionalização é o esforço consciente de integrar e infundir dimensões internacionais, interculturais e globais no ethos e nos resultados da educação póssecundária. Para ser plenamente bem sucedido, deve envolver o comprometimento ativo e responsável da comunidade acadêmica em redes globais e parcerias (NAFSA, 2011,p.1).

Em função das dificuldades de conceituação e das diferentes interpretações e proposições, Wit (2002, p. 114) diz "que na medida que a dimensão internacional do ensino superior ganha mais atenção e reconhecimento, as pessoas tendem a usá-lo da maneira que melhor se adéqua ao seu propósito".

Ao longo do tempo diversos autores identificam diferentes argumentos para internacionalização da educação. Aigner et al (1992) descreveram três razões para a internacionalização: salvaguardar a segurança internacional; manter a competitividade econômica; e promover a compreensão intercultural. Scott (1992) identificou como motivos específicos para a internacionalização do ensino superior: a competitividade; a interdependência ambiental; o aumento da diversidade étnica e religiosa de comunidades locais; a realidade de que muitos cidadãos trabalham para empresas estrangeiras; a influência do comércio internacional sobre pequenas empresas; o fato de que os graduados universitários supervisionarão ou serão supervisionados por pessoas de diferentes grupos raciais e étnicos e; a segurança nacional e as relações pacíficas entre as nações.

Em outro estudo Knight (1997) agrupa os possíveis argumentos para a internacionalização em quatro grupos: político, econômico, acadêmico e cultural/social. Os argumentos políticos incluem subcategorias como política externa, segurança nacional, assistência técnica, paz e compreensão mútua, identidade nacional e regional. Esses argumentos políticos foram importantes em todos os períodos, especialmente no Pós $2^{\text {a }}$ Guerra Mundial, período de reestruturação das relações com as antigas colônias e no processo de integração da União Europeia. Knight afirma que:

Historicamente a educação internacional é vista como uma ferramenta benéfica para a política internacional especialmente em relação à segurança internacional e a paz entre as nações. Embora isso continue a ser levado em consideração, não tem mais a mesma importância que já teve (1997, p. 9).

\begin{tabular}{l|l|l|l|l|l} 
(C) Rev. Inter. Educ. Sup. & Campinas, SP & v.3 & n.3 & p.604-623 & set./dez. 2017
\end{tabular}


Os argumentos econômicos incluem incentivos financeiros, mercado de trabalho, crescimento econômico e competitividade. Eles estão relacionados com os benefícios econômicos de curto e longo prazo. Benefícios de curto prazo significam antes de tudo as mensalidades e os outros recursos que os estudantes internacionais trazem consigo, durante sua estadia em um país. Com relação aos benefícios econômicos de longo prazo, os estudantes internacionais podem preencher à escassez de mão de obra e melhorar a capacidade de pesquisa de um país. As justificativas econômicas são atualmente consideradas como um dos principais motores das políticas de internacionalização em muitos países.

Outros autores enfatizaram a importância dos fatores econômicos nos processos de internacionalização do ensino superior. Davies (1992), por exemplo, acrescentou ao trabalho de Scott (1992) que a internacionalização está "intimamente ligada à redução financeira, à ascensão do empreendedorismo acadêmico e ao genuíno compromisso filosófico com as perspectivas transculturais no avanço e disseminação do conhecimento" (DAVIES, 1992, p. $56)$.

Murphy (2007) atesta os efeitos positivos dos esforços de internacionalização nos estudantes. Ela diz que os governos e as universidades consideram que os estudantes que estudam em universidades internacionalizadas demonstram maior conhecimento de eventos internacionais, perspectivas e métodos. Os alunos são vistos como melhor preparados para contribuírem positivamente ao progresso local, regional, nacional e internacional porque desenvolvem habilidades consideradas necessárias para a força de trabalho moderna e as condições globais, como a aquisição de uma segunda língua, sensibilização cultural, contatos internacionais e competências de adaptação.

O terceiro grupo de argumentos é o acadêmico, que inclui a dimensão internacional na pesquisa, no ensino e na extensão, a melhoria da qualidade das instituições com o objetivo de se alcançar padrões acadêmicos internacionais. Apesar do fato de que os argumentos econômicos estão se tornando importantes para internacionalização das instituições de ensino superior, argumentos educacionais e acadêmicos permanecem cruciais para a internacionalização das instituições de educação superior. Huisman e Van Der Wende (2004) consideram que, em contraste com as razões econômicas, os argumentos acadêmicos para a internacionalização contribuem com as políticas baseadas na cooperação, embora seja necessário ressaltar que caminham lado a lado a cooperação e a competição.

Quanto aos argumentos culturais e sociais, a internacionalização é muitas vezes considerada um meio importante de promover e preservar a cultura nacional em resposta aos processos de globalização. Nesse sentido, a internacionalização do ensino superior é vista como uma forma de garantir a diversidade cultural e étnica. Giang (2003) considera a justificação sociocultural como a preservação e a promoção da cultura nacional como motivação para os países que

\begin{tabular}{l|l|l|l|l|l|} 
(c) Rev. Inter. Educ. Sup. & Campinas, SP & v.3 & n.3 & p.604-623 & set./dez. 2017 \\
\hline
\end{tabular}


consideram a internacionalização como uma forma de respeitar a diversidade e contrabalançar o efeito homogeneizador percebido na globalização.

Os fundamentos originários do MOOC associados à perspectiva da internacionalização da educação, estão vinculados ao Open Educational Resources (OER). Conforme Santos (2013, p. 21), o termo OER foi criado no Forum on the Impact of Open Course Ware for Higher Education in Developing Countries, promovido pela UNESCO, no Massachusetts Institute of Technology (MIT), em 2002 e faz parte de um movimento de valorização do conhecimento aberto e massivo. A definição de OER contempla o reconhecimento dos recursos de ensino, aprendizagem e pesquisa em domínio público ou disponibilizados com uma licença de propriedade intelectual que permita seu uso e adaptação por terceiros. Cabe destacar que os materiais educacionais disponíveis na Internet gratuitamente sem licença não são considerados OER (SANTOS, 2013). O termo original do inglês, OER, foi utilizado e traduzido para o português em 2006 como Recursos Educacionais Abertos (REA), no contexto da expansão e na perspectiva do ensino superior a distância. Os REA fundamentamse na defesa da democratização do acesso à educação superior por meio de tecnologias como a Internet, wikis e ambientes de aprendizagem virtuais. Santos (2013, p. 22) afirma que com a expansão do ensino superior a distância no Brasil, cresce a possibilidade de criação dos REA (SANTOS, 2013).

O surgimento dos MOOCs estimula a criação e a defesa dos Recursos Educacionais Abertos (REA) e, portanto, promove a ideia de disponibilizar conteúdos e cursos, de forma livre e aberta, na perspectiva de contribuir com a difusão do conhecimento, da ciência e da academia; entretanto, a partir desta perspectiva, há certos desdobramentos práticos, destacando-se o surgimento de diferentes modelos, inclusive, na perspectiva oposta inerente ao modelo original, não abertos e não gratuitos. Assim, não se pode ignorar a relação próxima da expansão dos MOOCs tanto com a dimensão científico-acadêmica quanto da econômicopragmática da internacionalização da educação superior.

\section{A MERCANTILIZAÇÃo DA EDUCAÇÃo SUPERIOR}

As transformações na educação superior expressam um novo padrão de acumulação capitalista mundial que resultou no fortalecimento do protagonismo do empresariado no setor educacional. Chesnais (1996) refere-se a esta nova etapa de desenvolvimento do capitalismo como mundialização do capital, um modo de funcionamento do capitalismo baseado essencialmente na predominância do capital financeiro e rentista. Segundo o referido autor, o processo de desenvolvimento do capitalismo desenvolveu-se sob três dimensões principais: "intercâmbio comercial, investimento produtivo no exterior (IED) e os fluxos de capital

\begin{tabular}{|l|l|l|l|l|l|} 
(c) Rev. Inter. Educ. Sup. & Campinas, SP & v.3 & n.3 & p.604-623 & set./dez. 2017 \\
\hline
\end{tabular}


monetário, ou capital financeiro" (CHESNAIS, 1996, p. 51). Deste modo, atualmente, a mundialização do capital resulta num regime de acumulação ampliada de capital, cujos principais protagonistas são oriundos dos setores financeiros internacionais, que formam uma coalisão conflituosa e internacional que procuram interferir diretamente nas atividades políticas em nível mundial.

Conforme Chesnais (1996), o novo regime de acumulação, fomentado desde os fins da década de 1970, exige que os Estados Nacionais promovam reformas em benefícios das instituições financeiras. Essas reformas, invariavelmente, reafirmam a naturalidade e a predominância do mercado como meios para alcançar a estabilidade e o crescimento. Qualquer intervenção do Estado poderia produzir desequilíbrios, daí que convém estimular a diminuição dos aparatos e das políticas estatais de sua função de provedor de direitos e serviços sociais. Nesse contexto, o que está em jogo é não somente a destruição das regulamentações estatais, mas também a criação de novas relações sociais, segundo a própria lógica do mercado internacional. Conforme Dardot e Laval (2016, p. 24), toda a vida tende a estruturar-se agora segundo a racionalidade neoliberal, que não apenas criou um novo conjunto de regras para produzir um novo regime de acumulação, mas uma outra sociedade com características específicas própria do atual regime de expansão do capital.

O Brasil não está isento a tal racionalidade. No caso das instituições de ensino superior há vários autores que chamam a atenção para o fato de que as universidades estatais públicas estão se tornando uma empresa e se adequando a uma estrutura organizacional institucionalacadêmico gerencial. Especificamente, o modelo tradicional de universidade baseada no modelo “(...) alemão ou humboldtiano, constituído a partir das ideias de Von Humboldt, Fichte e Schleiermacher - liberdade de pesquisar, de aprender e de ensinar, e enciclopedismo (...)" (SGUISSARDI, 2011, p. 275), está sendo alterado em decorrência da predominância da racionalidade mercantil, configurando-se novos arranjos de ensino superior no Brasil e na criação de novas modalidade de educação. As notícias divulgadas nos jornais sobre aquisições bilionárias, fusões e expansões de grandes empresas educacionais exemplificam no cotidiano esse processo. A Folha de São Paulo, em 29/06/2016, publicou uma matéria anunciando que a rede de ensino privado Kroton Educacional e a Anhanguera Educacional produziriam uma fusão entre as operações das duas empresas, instituindo um gigante mundial do setor.

Esse processo inaugura novas transformações no ensino superior e revela a ampliação da lógica mercadológica na política de educação superior. Conforme Minto (2006), o protagonismo empresarial no ensino superior sempre esteve presente como resultado do forte processo de privatização. No período de 1933 e 1956 o crescimento do ensino privado se consolida e no período que vai de 1965 a 1980, há uma forte expansão quantitativa,

\begin{tabular}{l|l|l|l|l|l|} 
(ㄷ) Rev. Inter. Educ. Sup. & Campinas, SP & v.3 & n.3 & p.604-623 & set./dez. 2017 \\
\hline
\end{tabular}


decorrente da reforma de 1968 (MINTO, 2006). Atualmente, se considerar as matrículas no ensino superior, o Censo da Escolar do Ensino Superior de 2014 mostra que das 7.828.013 matriculas no ensino superior, $76 \%$ das matrículas são oriundas de instituições privadas. Do mesmo modo, no ensino a distância, no referido ano, mais de $70 \%$ das matriculas se concentra nas instituições privadas. Desta forma a tendência a privatização ocorre de forma direita (tradicional) e indireta atualmente com a predominância de uma gestão gerencial do próprio setor educacional público estatal em direção aos modelos empresariais de educação.

A mercantilização da universidade no país se dá a partir das proposições dos organismos multilaterais, como a Organização Mundial do Comércio (OMC), criada oficialmente em janeiro de 1995. Especificamente, no Acordo Geral sobre Comércio e Serviços (AGCS) do ano de 2000, proposta pela OMC, a educação se destacava como parte integrante do setor de serviços. Conforme Santos (2014, p. 910), a adesão pelo Brasil ao AGCS expressa a transformação da educação a partir de então em “(...) commodity que atrai capitais, mobiliza uma rede de distribuição para atender uma demanda emergente" (SANTOS, 2014, p. 910).

O Brasil aderiu inteiramente às recomendações dos organismos multilaterais desde meados da década de 1990, reelaborando e readequando seu arcabouço jurídico para atender a certas demandas, especialmente à desregulamentação do modelo tradicional nacional de ensino superior e ao devido ajuste às demandas de um modelo internacional, mais adequado às tecnologias de informação e comunicação e ao processo de internacionalização da educação, em conformidade à mundialização do capital. Conforme Silva Júnior, Mancebo e Schugurensky (2016), a elaboração do Plano Diretor da Reforma do Aparelho do Estado, liderada pelo Ministério da Administração Federal e da Reforma do Estado (MARE), no governo de Fernando Henrique Cardoso se constituiu em um passo importante para produzir a institucionalidade necessária para o alinhamento do país à nova etapa de acumulação do capital. Assim, paralelo ao reconhecimento da educação como parte do setor de serviços, as ações do governo incentivam os negócios dos investidores estrangeiros, com medidas de desregulamentação, privatização e desmonte do setor público. Há que destacar que o Brasil, a partir da elaboração do Plano Diretor da Reforma do Aparelho do Estado, em meados de 1995, tornou-se um mercado atrativo para os investimentos estrangeiros diretos (IED) conforme gráfico 1, necessitando adequar o ensino superior às exigências políticas, econômicas e acadêmicas internacionais. 


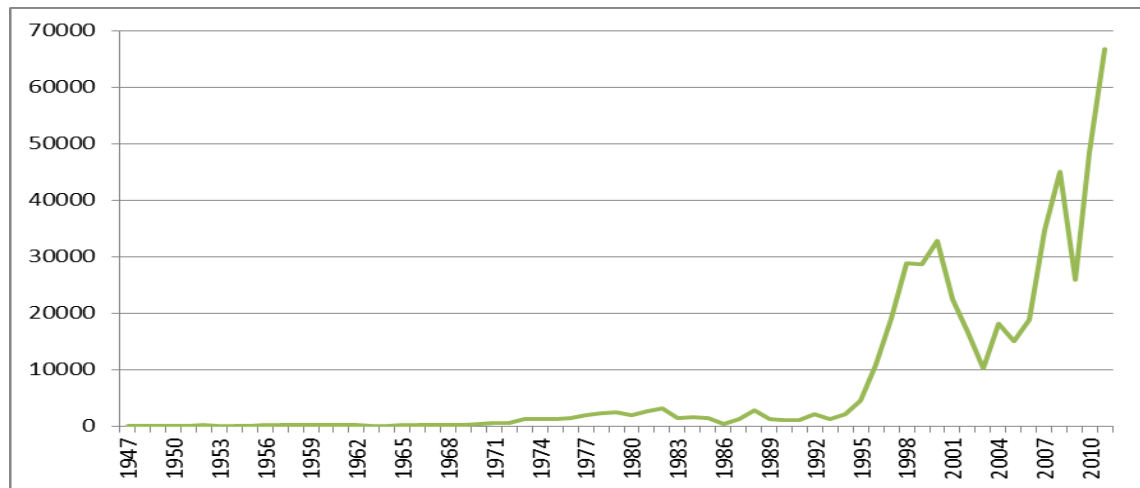

Gráfico 1. Investimentos Estrangeiro Direto no Brasil Fonte: Relatório de Inflação (2011)

Além da expansão da esfera mercantil na educação, outra consequência desse processo é a “(...) internacionalização da oferta com a penetração de grandes corporações multinacionais em países menos desenvolvidos" (OLIVEIRA, 2009, p. 740). Segundo dados da Organização para a Cooperação e Desenvolvimento Econômico (OCDE) o número de estudantes estrangeiros matriculados mundialmente aumentou $50 \%$ entre 2005 e 2012, cerca de 4.5 milhões de estudantes se matricularam fora de seus países de origem em 2012 e o número total alcançou os cinco milhões em 2014 (OCDE, 2015). No gráfico a seguir disponibilizado pela International Consultants for Education and Fairs, é possível observar a expansão significativa da mobilidade estudantil no período de 1990 a 2014:

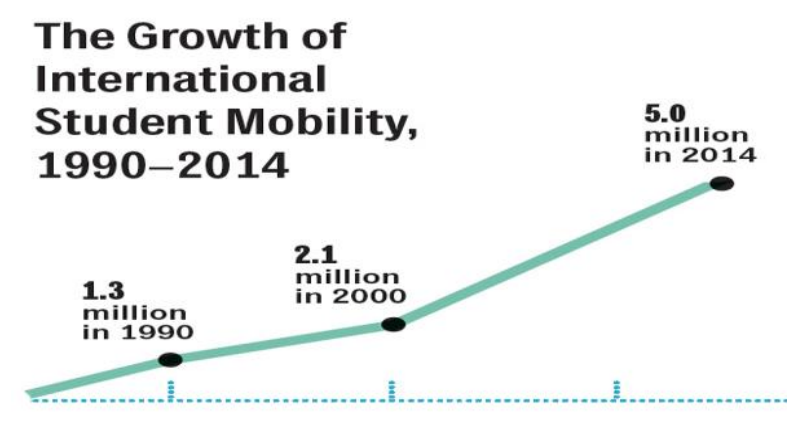

Gráfico 2. Título do gráfico

Fonte: International Consultants for Education and Fairs (2017).

No caso brasileiro, as políticas adotadas internamente colaboraram com as intencionalidades de expansão e de internacionalização da educação aos parâmetros do ensino superior internacional, especialmente aos modelos fundamentados nas tecnologias educativas e na gestão gerencial das instituições educacionais. O próprio Plano Nacional de Educação (PNE, 2014-2024), nas metas 12 e 14, trata da internacionalização da educação:

(C) Rev. Inter. Educ. Sup. Campinas, SP v.3 p.604-623 set./dez. 2017 
Meta 12: Consolidar e ampliar programas e ações de incentivo à mobilidade estudantil e docente em cursos de graduação e pós-graduação, em âmbito nacional e internacional, tendo em vista o enriquecimento da formação de nível superior;

[...]

Meta 14: Elevar o número de matrículas na pós-graduação stricto sensu, de modo a atingir a titulação anual de 60.000 mestres e 25.000 doutores; Expandir financiamento via agências oficiais de fomento; Expandir a oferta de cursos EAD; Reduzir as desigualdades étnico-raciais e favorecer o acesso; Interiorizar a PósGraduação stricto sensu (doutorado); Internacionalização da pesquisa e da pósgraduação (BRASIL, 2014, p.74-78).

Segundo Silva Júnior e Kato (2016), a operacionalização das ações delineadas no Plano Nacional de Educação foi instituída com o Decreto n. 7.642, de 13 de dezembro de 2011, na qual se instituiu o Programa Ciências sem Fronteiras cuja finalidade reside em "propiciar a formação e capacitação de pessoas com elevada qualificação em universidades, instituições de educação profissional e tecnológica, e centros de pesquisa estrangeiros de excelência" (SILVA JR. e KATO, 2016, p. 144). Segundo os autores, o Plano Nacional de Educação e Decreto n. 7.642/2011 criaram a agenda definitiva e consolidada da internacionalização no Brasil.

O conjunto das transformações econômicas e políticas adotadas no Brasil desde meados de 1990 revelam a tendência à expansão e à internacionalização da educação brasileira a partir da criação de uma nova racionalidade, que altera literalmente a concepção de educação reconhecida como bem público, configurando, portanto, nacionalmente, uma concepção fragmentada, minimalista e privatista, de Cursos Online Abertos e Massivos. A tendência é de que a integração do país ao desenvolvimento da economia mundial continue se desenvolvendo com base em políticas públicas que encorajam as iniciativas do setor privado e a desregulamentação das legislações em matéria educacional. Assim, para o país assegurar sua competitividade, as instituições de ensino superior são forçadas a se inovar e a criar novas arquiteturas institucionais e modalidades de educação mais flexíveis, contribuindo com a inserção do país à atual etapa de desenvolvimento do capitalismo.

\section{AS VICISSITUDES DOS MASSIVE OPEN ONLINE COURSE}

A internacionalização da educação superior tem provocado profundos impactos nas instituições de ensino superior, transformando-as mais amplamente a partir das possibilidades dos recursos tecnológicos e serviços virtuais, amplamente patrocinados e desenvolvidos por um modelo de Estado flexível e gerencial. Segundo Stallivieri (2009), as universidades acabam nesse contexto colaborando com a nova realidade mundial e disputando com as melhores instituições de ensino superior nacional e internacional em condições de igualdade (STALLIVIERI, 2009). Nessa perspectiva, os MOOCs tornam-se um estímulo e um forma de colaboração direta na indústria e no mercado tecnológico mundializado, na medida em que

\begin{tabular}{l|l|l|l|l|l} 
(c) Rev. Inter. Educ. Sup. & Campinas, SP & v.3 & n.3 & p.604-623 & set./dez. 2017 \\
\hline
\end{tabular}


incentiva o desenvolvimento informacional e tecnológico e, ao mesmo tempo, "favorecem a disseminação do conhecimento em grande escala e influenciam o processo de internacionalização, pois oportunizam a rápida aproximação de pessoas de diferentes origens e culturas" (BOAL e STALLIVIERI, 2015, p. 1). Assim, os MOOCs criados e idealizados inicialmente como um meio de difusão do conhecimento de modo gratuito e massivo, transformam sua proposta acadêmica inicial em um meio de incentivo à internacionalização da educação, conforme as regras e os valores próprios do mercado internacional da educação, com a privatização e o cerceamento/controle do conhecimento em um mercado mundial competitivo e monopolizador.

Goto (2015, p. 11) procura avaliar os possíveis impactos que os MOOCs podem provocar nas instituições de ensino superior. Para tanto realiza uma avaliação da dinâmica da competição institucional, concluindo que os MOOCs tendem a criar um ambiente de competição e rivalidade entre as instituições de ensino ao aumentar a busca/retenção dos melhores docentes, pois agregam visibilidade às instituições de ensino superior, com a evidenciação de seu status e de sua função social, além de elevar o padrão da qualidade do ensino (GOTO, 2015, p. 121).

Essa competição institucional deixa evidente que não se trata especificamente da competição entre as instituições de ensino superior, mas da competição entre os espaços físicos, naturais e sociais, de modo geral, geográficos, onde se situam regionalmente (país) as universidades sedes dos MOOCs. É, portanto, uma disputa por uma nova forma de colonização legalizada, regional, nacional e internacionalmente, com ares culturais e educacionais, em luta e disputa por um tipo novo de mercadoria, o conhecimento e a descoberta de nichos de mercado mundial (produção, comércio, força de trabalho, matéria prima, tecnologia). Por isso, o Programa Ciências sem Fronteiras se apresentar educacional e economicamente estratégico, isto é, uma forma evidente de internacionalização da educação, vinculado a interesses e estratégias em competição entre burguesia nacional e internacional, mediados pelo Estado.

A literatura nacional e internacional evidencia o papel relevante que os MOOCs ocupam na gestão estratégica universitária, atuando também como um modo de visibilidade/reforço da marca/renome da instituição universitária ou funcionando como mostruário para seus cursos e para a instituição em amplos espaços geográficos, constituindo uma forma de ampliação do prestigio; a partir desse novo rearranjo a universidade se articula para atrair novos alunos e ampliar suas matrículas. Porém, o fenômeno ocorre apenas quando a instituição de ensino superior já está estabelecida no mercado, já que apenas o MOOC não tem capacidade de por si mesmo transpor as barreiras universitárias e adquirir um nicho próprio de mercado; desta forma os MOOCs adquirem relevância na medida em que atrelada a uma instituição de ensino superior e servindo aos seus interesses para contribuir com a internacionalização da educação

\begin{tabular}{l|l|l|l|l|l}
\hline () Rev. Inter. Educ. Sup. & Campinas, SP & v.3 & n.3 & p.604-623 & set./dez. 2017 \\
\hline
\end{tabular}


superior, constituindo esta sua principal relevância (GOTO, 2015, p. 63).

A Open University e a Massive Open Online Course se diferenciam entre si justamente pela função social (e política) que possuem no processo de escolarização, expansão e democratização da educação. Diferentemente dos cursos de educação a distância que adquirem/assemelham a uma organização e estruturas próprias de uma instituição de ensino superior e que podem ou não estar atrelados a uma universidade presencial em específico, a capacidade de criação ou expansão dos MOOCs, ao contrário, depende diretamente do prestigio universitário de uma universidade, por mais contraditório que pareça necessitam de uma localidade física e geográfica da universidade referência, de uma referência à excelência e à meritocracia do curso e seus docentes bem como da universidade e do seu país. Assim, a capacidade de popularização e generalização da educação a distância é demasiadamente maior à dos MOOCs, não por motivos tecnológicos, mas por estratégia mesma de democratização, é uma questão político-estratégica. Há uma confusão que maximiza o entendimento de ensino a distância e os MOOCs como mesma modalidade por causa do uso dos recursos informacionais e tecnológicos, e minimizam o aspecto político-democrático do entendimento do que se pode compreender como acesso livre e aberto, especificamente sobre o que se deve entender por acesso livre e aberto. Não parece adequado subjugar/menosprezar a questão política dos MOOCs e sua relação com a internacionalização da educação superior, na medida em que esta educação ocorre vinculado a um movimento de mundialização do capital. Em termos mais limitados, ambas possuem uma concepção de educação bastante diferenciadas em cursos e em abrangência geográfica dos alunos, a clientela no caso dos MOOCs tende a ser mais selecionada, enquanto na $\mathrm{EaD}$ pode ser bem diversa e no Brasil se compactua, de alguma forma, com a necessidade de interiorização/democratização do ensino superior.

Assim, a modalidade de EaD está mais próxima do ensino superior presencial do que propriamente os MOOCs, cujos cursos não são efetivamente cursos superiores, mas tão somente formação ou qualificação, em outros termos, cursos de complementação, apesar das suas múltiplas possibilidades e flexibilidades; além do mais ser livre e aberto adquire outra conotação, pois não há preocupação com o objetivo explícito de regionalização ou interiorização do ensino superior, em termo mais progressistas, em democratização do ensino. Está se tratando, portanto, de outra concepção de educação superior, que não tem paralelo ente internacionalização/mundialização e regionalização/democratização da educação. São duas lógicas e dois modelos de ensino superior, ressalvado às próprias críticas à $\mathrm{EaD}$. $\mathrm{O}$ que caracteriza os MOOCs sem preocupação primária e efetiva com a expansão do ensino superior, no entanto, mais estritamente com o desenvolvimento cientifico e tecnológico e com as necessidades mercadológicas da burguesia.

(C) Rev. Inter. Educ. Sup.

Campinas, SP

v.3

n.3

p.604-623

set./dez. 2017 
Está evidente que Massive Open Online Course possui uma vicissitude que permite a confusão dos termos, dos objetivos e das finalidades, que não permite uma precisa definição sobre métodos de ensino que a diferença da educação a distância, conferindo às tecnologias da informação e comunicação uma importância maior do que a verdadeiramente devida. $O$ essencial no estudo e na interpretação dos MOOCs é que sua análise deve estar vinculada ao contexto de sua própria existência, a internacionalização da educação superior e às estratégias da mundialização do capital.

\section{CONSIDERAÇõES FINAIS}

Analisou-se no artigo os Cursos Online Aberto e Massivo (Massive Open Online Course MOOC), contextualizando com a referência aos estudos sobre processos de mundialização do capital e, em específico, com os estudos sobre os processos de internacionalização do ensino superior. Defendeu-se a tese de que somente é possível compreender plenamente os MOOCs se não se comparar às análises propriamente didático-pedagógicas alinhadas ao modelo da educação a distância, e nem especialmente à centralidade das tecnologias da informação e comunicação, como principal fator de definição. Conclui-se que mesmo que os MOOCs tenham incialmente surgido como um meio democrático de difusão do conhecimento de modo gratuito e massivo, sua proposta inicial se descaracteriza, em conformidade às regras e valores próprios do mercado internacional da educação.

\section{REFERÊNCIAS}

AIGNER, Jean. S.; NELSON, Patricia; STIMPFL, Joseph. R. Internationalizing the University: making it work. Springfield: CBIS Federal, 1992.

ARUM, S.; WATER, J. Van de. Necesidad de una definición de educación internacional en las universidades de Estados Unidos: puente para los futuros. In: KLASEK, C. (Ed.).

Strategies for internationalizing higher education. [S.1.]: Asociación de administradores de Educación Internacional, 1992.

BANCO CENTRAL DO BRASIL. (Brasil). Evolução dos Fluxos de Investimento Estrangeiro Direto. In: RELATÓRIO de Inflação. set. 2011. Disponível em: <http://www.bcb.gov.br/htms/relinf/port/2011/09/ ri201109b5p.pdf>. Acesso em: 15 set. 2016.

BIAGIOTTI, Breno de Almeida. Avaliação da qualidade da informação de Cursos massivos: um estudo de caso do telelab. 2016. 140f. Dissertação (Mestrado em Engenharia e Gestão do Conhecimento) - Universidade Federal de Santa Catarina, Santa Catarina, 2016.

\begin{tabular}{|l|l|l|l|l|l|}
\hline C) Rev. Inter. Educ. Sup. & Campinas, SP & v.3 & n.3 & p.604-623 & set./dez. 2017 \\
\hline
\end{tabular}


BOAL, Helena Maria Chaves; STALLIVIERI, Luciene. Os Moocs e o Processo de Internacionalização das Instituições de Ensino Superior. COLÓQUIO INTERNACIONAL DE GESTÃO UNIVERSITÁRIA - CIGU DESAFIOS DA GESTÃO UNIVERSITÁRIA NO SÉCULO XXI, 15.:2015: Mar del Plata, Argentina. [Annales del...]. Mardel Plata, Argentina: [s.n.], 2015.

BOTTENTUIT JUNIOR, João. Batista. Cursos Online Abertos e Massivos (MOOCS): possibilidades de formação continuada a distância. TICs e EAD em foco, v.1, n. 1, 2015. Disponível em: <htp://www.uemanet.uema.br/revista/index.php/ticseadfoco/article/ download/2/pdf>. Acesso em: 27 mar. 2017.

BRASIL. Lei n. 13.005, de 25 de junho de 2014. Aprova o Plano Nacional de Educação PNE e dá outras providências. Diário Oficial da União (República Federativa do Brasil), Brasília, DF, Seção 1, Edição Extra, 26 jun. 2014, p.1 (Publicação Original). Disponível em:

<http://www2.camara.leg.br/legin/fed/lei/2014/lei-13005-25-junho-2014-

778970- publicacaooriginal-144468-pl.html>. Acesso em: 27 mar. 2017.

CANDIDO, Roseane Souza. Desenvolvimento de Aplicações Educacionais com

Realidade Aumentada para um Curso Aberto Massivo Online de Histologia. 2013. 15f. Dissertação (Mestrado em Ensino de Ciências)-Universidade Federal de Itajubá, Itajubá, 2013.

CHESNAIS, François. A mundialização do capital. São Paulo: Xamã, 1996.

CHIZZOTTI, Antônio. Educação Superior e o Mercado de Serviços Educacionais. Revista e-Curriculum, São Paulo, v.12, n.1, janeiro/abril 2014. Disponível em:

<https://revistas.pucsp. br//index.php/curriculum/article/view/19791/14723>. Acesso em 8 abr. 2017.

CUNHA, Joana. Kroton aumenta oferta e conselho da Estácio diz que aceita fusão. Jornal Folha de São Paulo. Mercado, 1 jul. 2016. Disponível em:

<http://www1.folha.uol.com.br/ mercado/2016/07/1787560-kroton-aumenta-oferta-econselho-da-estacio-diz-que-aceita- fusao.shtml>. Acesso em: 8 abr. 2017.

DARDOT, Pierre; LAVAL, Christian. A nova razão do mundo: ensaio sobre a sociedade neoliberal. São Paulo: Boitempo, 2016.

DAVIES, John. Developing a Strategy for Internationalizing in Universities: Towards a conceptual framework, 1992. Policy Futures in Education, v.1, n. 2, 2003. Disponível em: <https://www.ses.unam.mx/docencia/2007II/Lecturas/Mod2_Qiang.pdf>. Acesso em: 27 mar. 2017.

DE WIT, H. Internationalization of Higher Education in the United States of America

(C) Rev. Inter. Educ. Sup. Campinas, SP v.3

n. 3 p.604-623 set./dez. 2017 
and Europe: a historical, comparative, and conceptual analysis. Westport: Greenwood Press, 2002.

EBONE, Denise Santin. Avaliação e Seleção de Plataforma para Cursos Online Abertos e Massivos em Instituições de Ensino Superior. 2015. 105f. Dissertação (Mestrado em Engenharia e Gestão do Conhecimento) - Universidade Federal de Santa Catarina, Florianópolis, 2015.

FORNO, Josiane Pozzatti Dal.; KNOL, Graziela Frainer. Os moocs no mundo: um levantamento de cursos online abertos massivos. Nuances: estudos sobre Educação, Presidente Prudente, v.24, n.3, p.178-194, set./dez. 2013.

GOTO, Melissa Midori Martinho. O impacto dos MOOCs (Massive Open Online Courses) nas instituições de ensino superior: um estudo exploratório. 2015. $213 \mathrm{f}$. Dissertação (Mestrado em Administração) - Universidade de São Paulo, São Paulo, 2015.

HUISMAN, Jeroen; VAN DER WENDE, Marijk. (Ed.). On cooperation and competition: national and european policies for the internationalisation of higher Eduction. Bonn, Germany: Lemmens, 2004.

INSTITUTO NACIONAL DE ESTUDOS E PESQUISAS EDUCACIONAIS ANÍSIO TEIXEIRA LEGISLAÇÃO E DOCUMENTOS (INEP). (Brasil). Sinopses estatísticas do Censo da Educação Superior: 1995 a 2010. Brasília, 2015-2016. Disponível em: <http://www.inep.gov.br/superior/censosuperior/ sinopse/default.asp>. Acesso em: 10 fev. 2017.

KNIGHT, Jane. Internationalization of Higher Education: a conceptual framework.In: KNIGHT, Janet; DE WIT, Hans (Ed.). Internationalization of higher education in Asia Pacific Countries. Amsterdam: European association for International Education, 1997. p.5- 19

KNIGHT, Jane. Updating the Definition of Internationalization. International Higher Education. Boston, n.33, p.2-8, Autum, 2003a.

KNIGHT, Jane . Internationalization of higher education practices and priorities. IAU Survey Report. 2003b. Disponível em: <http://www.unesco.org/iau/internacionalization/pdf/ Internacionalisation-en.pdf > Acesso em: 15 maio 2017.

KNIGHT, Jane . Un modelo de internacionalización. Respuestas a nuevas realidades y retos. In: DE WIT, Hans et al. (Ed.). Educación superior en América Latina: la dimensión internacional. Bogotá: Banco Mundial; Mayol Ediciones, 2005.

MANCEBO, Deise; SILVA JUNIOR, João dos Reis; SCHUGURENSKY, Daniel.

(C) Rev. Inter. Educ. Sup. Campinas, SP v.3 p.604-623 set./dez. 2017 
Brazilian higher education in face of capital globalization. Educação em Revista, v.32, n.4, p.205- 225, 2016. Disponível em: < http://dx.doi.org/10.1590/0102-4698162033>. Acesso em: 10 maio 2016.

MARQUES, Paula Fogaça. Massive Open Online Course (Mooc): uma análise de experiências pioneiras. 2015. 10f. Dissertação (Mestrado em Educação) - Universidade Federal do Rio Grande do Sul, Porto Alegre, 2015.

MINTO, Lalo Watanabe. As reformas do ensino superior no Brasil: o público e o privado em questão. Campinas, SP: Autores Associados, 2006.

MURPHY, M. Experiences in the internationalization of education. strategies to promote equality of opportunity at monterray tech. Ciudad Juarez, Mexico. Higher Education. v.53, n.2, p.167-208, 2007.

NAFSA: ASSOCIATION OF INTERNATIONAL EDUCATORS. The economic benefits of international education to the United States for the 2008-2009 academic year, 2010: a statistical analysis. Disponível em: 〈https://www.nafsa.org/_/File/_/eis2011/USA.pdf>. Acesso em: 10 maio 2017.

\section{NAFSA: ASSOCIATION OF INTERNATIONAL EDUCATORS. Contribution to}

Internationalization of Higher Education. 2011. Disponível em:

<https://www.nafsa.org/_File/_/2011_izn_contributions.pdf>. Acesso em: 11 maio 2017.

OLIVEIRA, Dessano Plum. Desenvolvimento e avaliação de um Curso Aberto Massivo online sobre anatomia baseado em redundância, interatividade e estilos de coaprendizagem. 2015. 223f. Dissertação (Mestrado em Ensino em Ciências) Universidade Federal de Itajubá, Itajubá, 2015.

OLIVEIRA, Romualdo Portela. A transformação da educação em mercadoria no Brasil.

Educação e Sociedade. Campinas, vol. 30, n. 108, p. 739-760, out. 2009739 Disponível em: http://www.scielo.br/pdf/es/v30n108/a0630108.pdf. Acesso em: 08 abr. 2017.

OSCAR, Naiana. Grupo americano, dono da Anhembi Morumbi, compra FMU por R\$ 1 bi. O Estado de São Paulo, São Paulo, 23 ago. 2013. Disponível em:

$<$ http://economia.estadao.com.br/noticias/negocios,grupo-americano-dono-daanhembi-morumbi-compra-fmu-por-r-1-bi,162651e >. Acesso em: 10 abr. 2007.

ORGANISATION FOR ECONOMIC CO-OPERATION AND DEVELOPMENT (OECD). Internacionalization and trade of higher education: opportunities and challenges. Paris: Organization for Economic Cooperation and Development. 2004. Disponível em: <https://www.oecd.org/edu/skills-beyond-school/33730019.pdf>. Acesso em: 11 maio 2017.

QIANG, Zah. Internationalization of higher education: towards a conceptual framework.

(C) Rev. Inter. Educ. Sup. v.3 n.3 set./dez. 2017 
Policy Futures in Education, v.1, n.2, 2003.

SANTOS, Andreia Inamorato. Open educational resources in Brazil: state-of-the-art, challenges and prospects for development and innovation. Moscow: UNESCO, 2013.

SCHOELLER, Igor Dorneles. Elaboração, aplicação e avaliação de um Curso Online Aberto e Massivo (MOOC) interdisciplinar entre Física e Matemática. 2015. 127f. Dissertação (Mestrado em Ensino de Física - PROFIS) - Universidade Federal De Santa Catarina, Santa Catarina, 2016.

SCOTT, Robert Allyn. Campus developments in response to the challenges of internationalization: The case of Ramapo College of New Jersey (USA). Higher Education Management, v.6, n.1, p.71-89, 1992.

SGUISSARDI, Valdemar. Universidade no Brasil: dos modelos clássicos aos modelos de ocasião? In: MOROSINI, Marília. (Org). A universidade no Brasil: concepções e modelos. Brasília: Instituto Nacional de Estudos e Pesquisas Educacionais Anísio Teixeira, 2006.

Disponível em: <http://flacso.redelivre.org.br/files/2012/07/341.pdf\#page=277>. Acesso em: 9 abr. 2017.

SILVA JÚNIOR, João dos Reis; KATO, Fabíola Bouth Grello. A política de internacionalização da educação superior no plano nacional de pós-graduação (2011-2020). Revista Internacional de Educação Superior, Campinas, v.2, n.1, p.138-151, janeiro/abril 2016. Disponível em: <http://ojs.fe.unicamp.br/index.php/RIESup/article/view/7543 >. Acesso em: 8 abr. 2017. doi:https://doi.org/10.22348/riesup.v2i1.7543.

SOUZA, Maria José Guimarães. de. Mooc de Geometria: discussões e proposta de um modelo para a educação básica. 2015. 32f. Dissertação (Mestrado em Ciência da Computação) - Universidade de São Paulo, São Paulo, 2015.

SOUZA, Rodrigo De. Origens da vida no contexto cósmico: estudo sobre o desenvolvimento de MOOC em Astronomia. 2016. 104f. Dissertação (Mestrado em Ensino de Astronomia) - Universidade de São Paulo, São Paulo, 2016.

STALLIVIERI, Luciene. Estratégias de Internacionalização das Universidades Brasileiras. Caxias do Sul: EDUCS, 2004.

VAN DER WENDE, Marijk. Internationalization of higher education in the OECD countries: Challenges and opportunities for the coming decade. Journal of Studies in International Education, v.11, n.3-4, p.274-289, 1997. Disponível em http://journals.sagepub.com/doi/pdf/10.1177/1028315307303543. Acesso em 8 abr. 2017.

VAN DER WENDE. Missing links: The Relationship between National Policies for

\begin{tabular}{|l|l|l|l|l|l} 
(C) Rev. Inter. Educ. Sup. & Campinas, SP & v.3 & n.3 & p.604-623 & set./dez. 2017
\end{tabular}


Internationalisation and those for Higher Education in General. In: KALVERMARK, T.; VAN DER WENDE, Marikj. (Ed.). National Policies for the Internationalization of Higher Education in Europe. Hogskoleverket Studies. Estocolmo: Agencia Nacional para la Educación Superior, p.10-31, 1997.

YUAN, L.; POWELL, S.; ECETIS, J. MOOCs and open education: implications for higher education. Cetis White Paper 2013. Disponível em: <http://www.smarthighered. com/wpcontent/uploads/2013/03/MOOCs-and-Open-Education.pdf >. Acesso em: 9 jul. 2014.

ZANINI, Joice Maria. O MOOC (Massive Open Online Course) e o ensino de Biologia. 2016. 134f. Trabalho de Conclusão de Curso (Título de Bacharel em Ciências Biológicas) - Escola Superior de Agricultura “Luis de Queiroz”, Piracicaba, 2016.

\section{${ }^{\mathrm{i}}$ Sobre os autores}

Tânia Barbosa Martins

E-mail: taniabmartins@yahoo.com.br / ORCID: http://orcid.org/0000-0003-4095-4995

Universidade Metodista de Piracicaba - Brasil

Doutorado e Educação pela Universitária Federal de São Carlos [UFSCar].

\section{Marcelo da Silva Leite}

E-mail: masleite07@gmail.com / ORCID: http://orcid.org/0000-0003-3713-7433

Universidade Metodista de Piracicaba - Brasil

Doutorando em Educação pela Universidade Metodista de Piracicaba [UNIMEP].

\section{Miriam Pavany}

E-mail: mpavany@gmail.com / ORCID: http://orcid.org/0000-0003-2955-2928

Universidade Metodista de Piracicaba - Brasil

Doutorando em Educação pela Universidade Metodista de Piracicaba [UNIMEP]. 